\title{
AL-AWQAF
}

Jurnal Wakaf dan Ekonomi Islam

Vol. 14, No. 2, Tahun 2021

\section{Analisis Persepsi Wakif Terhadap Wakaf Tunai di BWI Sumatera Utara}

\author{
Imsar $^{1}$, Khairina Tambunan ${ }^{2}$, Franaya $\mathrm{Al} \mathrm{Arfa}^{3}$ \\ ${ }^{1}$ Universitas Islam Negeri Sumatera Utara, imsar@uinsu.ac.id \\ 1 Universitas Islam Negeri Sumatera Utara, imsar@uinsu.ac.id, khairinatambunan@uinsu.ac.id \\ ${ }^{1}$ Universitas Islam Negeri Sumatera Utara, imsar@uinsu.ac.id, nayyaarfa14@gmail.com
}

\begin{abstract}
The purpose of this study was to determine the perception of wakif on cash waqf at BWI North Sumatra. This study uses a descriptive qualitative method, by taking the object of research at BWI North Sumatra. As the research informant, Nazhir from BWI North Sumatra, the wakif. This study explains that there are 5 indicators used to measure the perception of wakif, namely internal indicators consisting of income and understanding, and external indicators, namely information media, convenience and benefits of cash waqf at BWI North Sumatra. Based on the results of the data questionnaire assessment, that $73.3 \%$ of wakif stated that it was good from the income indicator. This means that wakifs have a good perception of cash waqf that the more prosperous the community, the greater the potential for cash waqf. From the indicators of understanding, $46.7 \%$ of wakifs said they were good with cash waqf. That is, wakif has a good perception of cash waqf in terms of understanding so that awareness arises in advancing the Islamic economy through cash waqf. From the information media indicators, $43.3 \%$ of wakif stated that they were neutral towards the perception of wakif in terms of access to information media. This means that BWI SU should further promote information media through online media in the digital era. From the convenience indicator $46.7 \%$ wakif answered well. This means that wakifs have a good perception of the convenience provided in accessing BWI SU for cash waqf collection transactions for wakifs. From the benefits indicator $56.7 \%$ wakif answered well. This means that wakifs have a good perception of the benefits of cash waqf, which can train the social spirit and help people in need.
\end{abstract}

Keywords: Perception, Cash Waqh, BWI Sumatera Utara

Abstrak: Penelitian ini bertujuan mengetahui persepsi wakif terhadap wakaf tunai di BWI Sumatera Utara. Penelitian ini menggunakan metode kualitatif deskriptif, dengan mengambil objek penelitian di BWI Sumatera Utara (SU). Sebagai informan penelitian adalah wakif yang berwakaf kepada Nazhir BWI Sumatera Utara dan perwakilan dari nazhir. Penelitian ini menggunakan 5 indikator untuk mengukur persepsi wakif, yaitu pendapatan, pemahaman, media informasi, kemudahan, dan manfaat wakaf. Dari hasil penilaian angket data diketahui bahwa $73,3 \%$ wakif menyatakan baik dari indikator pendapatan. Artinya, wakif memiliki persepsi yang baik mengenai wakaf tunai bahwa semakin sejahtera masyarakat maka potensi wakaf tunai juga semakin besar. Dari indikator pemahaman menunjukkan 46,7\% wakif menyatakan baik dengan wakaf tunai. Artinya, wakif memiliki persepsi yang baik terhadap wakaf tunai dari sisi pemahaman sehingga muncul kesadaran dalam memajukan ekonomi islam melalui wakaf tunai. Dari indikator 
media informasi bahwa 43,3\% wakif menyatakan netral terhadap persepsi wakif dari sisi akses media informasi. Artinya, BWI SU agar lebih menggalakkan media informasi melalui media online di era digital. Dari indikator kemudahan 46,7\% wakif menjawab baik. Artinya wakif memiliki persepsi yang baik tentang kemudahan yang diberikan dalam mengakses BWI SU untuk transaksi penghimpunan wakaf tunai bagi wakif. Dari indikator manfaat 56,7\% wakif menjawab baik. Artinya wakif memiliki persepsi yang baik tentang manfaat wakaf tunai dapat melatih jiwa sosial dan membantu umat yang kesulitan.

Kata Kunci: Persepsi, Wakaf Tunai, BWI Sumatera Utara

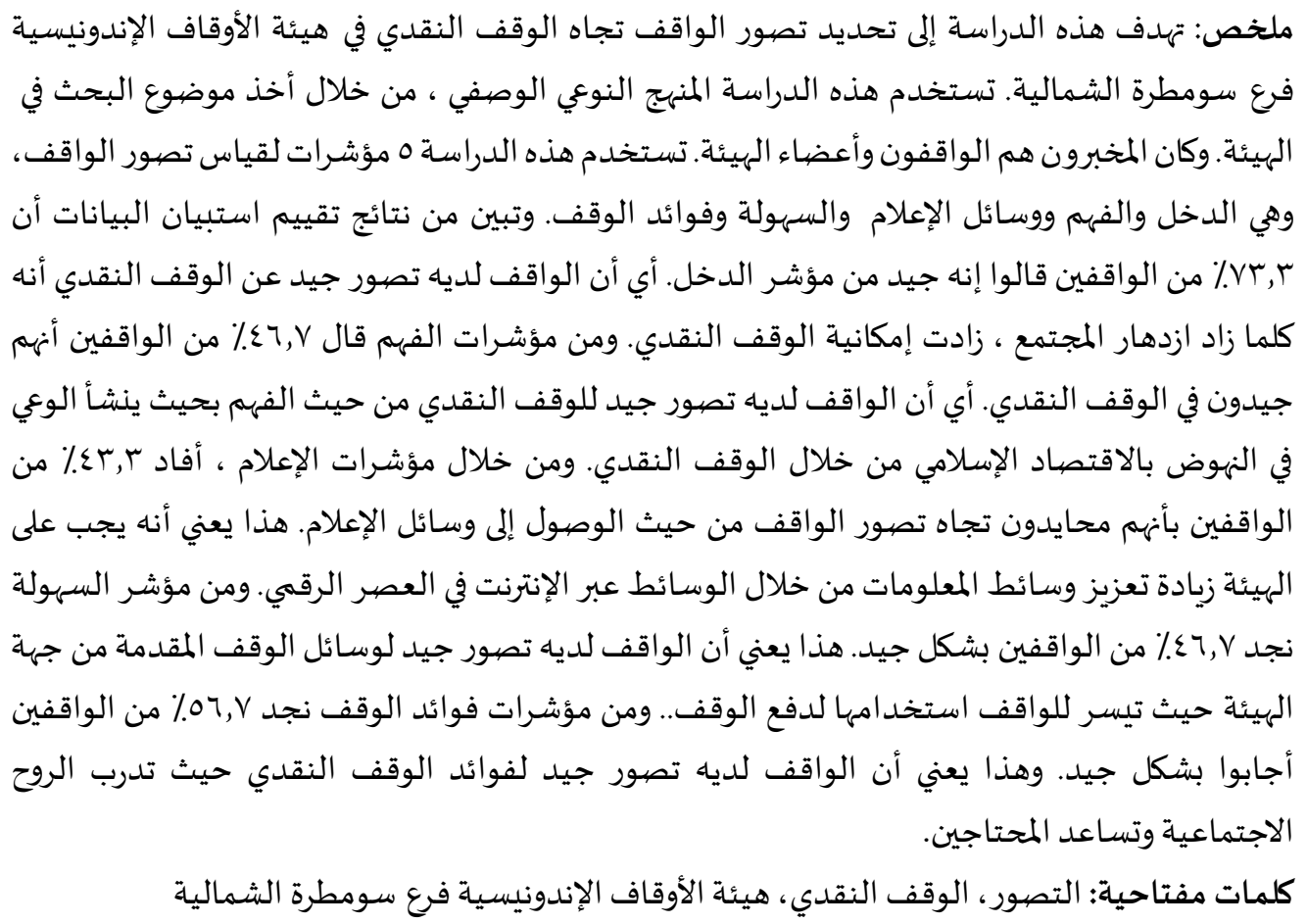

\section{PENDAHULUAN}

Wakaf merupakan filantrofi Islam terbaik dalam bentuk dana sumbangan. Selain dari aspek ibadah, wakaf memiliki hubungan hukum, sosial, dan terutama ekonomi yang sangat kuat. Islam telah lama mengenalkan solusi atas masalah yang dihadapi masyarakat terhadap kemiskinan dan kesejahteraan dengan adanya berbagai instrumen filantropi termasuk wakaf. Wakaf bukan hanya aspek spiritual, tetapi juga merupakan bentuk pendidikan islam dengan aspek sosial (Rahardjo, 2019).

Wakaf di Indonesia mempunyai potensi yang terbilang cukup besar pengelolaan kekayaan wakaf masih tidak produktif. Usaha pengembangan harus dilakukan agar memproduktifkan wakaf adalah dengan adanya wakaf tunai. Tetapi realisasinya masih lumayan jauh dari tingginya potensi yang ada. Salah satu penyebabnya ialah minimnya literasi masyarakat terhadap wakaf tunai sehingga membuat persepsi masyarakat masih terpaku pada jenis harta wakaf seperti masjid, makam dan harta tidak bergerak lainnya.

Ada lembaga wakaf yang khusus mengelola dana wakaf dan berjalan secara nasional yaitu Badan Wakaf Indonesia Sumatera Utara. Tugasnya adalah mengawasi dan membina nazhir dan mengelola secara sendiri harta wakaf yang diwaqafkan kepadanya, terkhususnya wakaf tunai. 
BWI adalah badan independen yang didirikan berdasarkan Undang-Undang Nomor 41 Tahun 2004. Ketetapan tersebut langsung oleh Presiden, yang dibentuk untuk melindungi, dan mengelola asset wakaf dan mengembangkannya menjadi asset yang produktif untuk mendapat keuntungan. Di kalangan masyarakat, dengan demikian harta wakaf Indonesia sangat penting, tersebar luas dan banyak yang tidak produktif.

Pesatnya perkembangan sistem ekonomi Islam Indonesia dan penerimaan umum terhadap wakaf seharusnya tidak hanya menjadikan wakaf tunai sebagai wacana penting, tetapi juga harus adanya pengembangan untuk wakaf tunai.

Wakaf tunai menawarkan keleluasaan untuk membuka peluang wakaf kepada semua orang, tergantung pada kemampuan dan integritas, serta untuk mengakumulasikan asset wakaf dan menggunakannya secara lebih berarti sesuai kebutuhan aktual umat. Wakaf uang sebagai dana pihak ketiga untuk mempercepat perkembangan keuangan perbankan syariah dan konsekuensinya akan digunakan untuk meningkatkan perekomian masyarakat (Amiur Nuruddin, 2009.

Menurut catatan BWI Indonesia, jumlah wakaf tunai terkumpul sampai tahun 2020 mencapai Rp391 miliar. Melihat potensi untuk wakaf tunai tahun ini sebesar Rp180 triliun. Ini terjadi karena minimnya literasi, portofolio wakaf, dan juga kemudahan (keringanan) cara untuk berwakaf. Data BWI Indonesia hingga per 20 Januari 2021, wakaf tunai mencapai Rp819,36 miliar. Yang terdiri dari wakaf melalui tunai Rp580,53 miliar dan wakaf tunai sebesar Rp238,83 miliar. Sementara, jumlah nazir di Indonesia mencapai 264 lembaga, dan jumlah LKS-PWU ada 23 Bank Syariah.

Potensi wakaf tunai di Sumatera Utara mencapai Rp. 3 Miliyar, dan sedangkan realisasi wakaf tunai di BWI Sumatera Utara sebesar Rp. 500 Juta. Artinya 16,7\% dari potensi wakaf yang ada masih dapat dimanfaatkan dan masih memiliki potensi yang besar ketika wakaf tunai dikembangkan.

Untuk meningkatkan pengumpulan wakaf tunai juga penting untuk meningkatkan kesadaran masyarakat untuk menjadi wakif seperti melalui pemahaman atau persepsi sebagai wakif yaitu dengan adanya pandangan seseorang mengenai wakaf tunai dari indikator internal dan eksternal. Dalam penelitian ini penulis membatasi indikator internal pada pendapatan dan pemahaman. Sedangkan dari indikator eksternal dibatasi pada media informasi, kemudahan dan manfaat wakaf tunai di BWI SU.

Berbagai fenomena dan permasalahan di BWI SU tentang hambatan perkembangan wakaf tunai khususnya seperti permasalahan minimnya (kurangnya) realisasi penghimpunan wakaf tunai karena disebabkan kurangnya literasi (pengetahuan) serta pemahaman masyarakat sebagai calon dan sebagai wakif (Machmud et al, 2020). BWI SU terlebih khususnya dalam menjalankan tugasnya yaitu dengan mensosialisasikan wakaf uang di era digital harusnya sudah melalui penggunaan media massa, seperti media elektronik, media cetak dan juga media internet sehingga dengan adanya media ini memberikan kemudahan. Akan tetapi penggunaan media massa ini belum berhasil mensosialisasikan wakaf tunai, dan juga dibuktikan dengan pola pikir 
masyarakat yang masih kurang mengenai wakaf itu berbentuk benda tidak bergerak dan dijadikan sarana yang kurang produktif (Ahmad Nizar, 2014)

Distribusi pendapatan dalam konteks mikro akan berkaitan dengan sedekah yang dapat dipahami melalui dua aspek yaitu sedekah wajib dan juga sedekah sunnah. Masyarakat di Indonesia mengetahui sedekah wajib dalam bentuk zakat sedangkan sedekah sunnah yaitu adalah infak, akikah, wasiat dan juga wakaf (Cupian et al,. 2020)

Penelitian ini bertujuan mengetahui bagaimana persepsi wakif terhadap wakaf tunai di BWI Sumatera Utara. Ada lima indikator yang digunakan untuk mengukur persepsi tersebut, yaitu pendapatan, pemahaman, media informasi, kemudahan, dan manfaat wakaf. Dua indikator pertama adalah indikator internal, sedangkan tiga indikator terakhir adalah indikator eksternal.

\section{KAJIAN TEORI}

\section{Wakaf Tunai}

Wakaf tunai adalah wakaf yang dilaksanakan dalam bentuk uang (tunai) oleh perorangan, sekelompok orang atau suatu lembaga seperti saham dan cek. Secara umum pengertian wakaf tunai adalah pemberian harta wakaf berupa uang tunai yang tidak dapat dialihkan atau dibekukan karena alasan untuk kepentingan umum. Dalam pengertian yang lain, wakaf tunai adalah wakaf yang dilakukan seseorang, kelompok orang yang tidak dapat mengurangi atau menhilangkan pokok (inti dariwakaf). Salah satu bentuk gerakan wakaf yang banyak mendapat perhatian dari para ulama adalah dikenal wakaf tunai.

\section{Wakif}

Pewakif atau wakif adalah pihak yang menyumbangkan hartanya. Wakif juga memiliki kemampuan melakukan tabarru' yang berarti melepaskan hak milik tanpa pertimbangan yang berarti bahwa mereka sehat, dan tak terpaksa melakuannya. Sulaiman Rasyid menjelaskan dalam bukunya yaitu Fikih Islam bahwa masa remaja berfokus pada usia tua dan berkaitan dengan kematangan jiwa atau kematangan spiritual (Rashid, 2011).

Wakif meliputi orang atau organisasi, atau lembaga (badan hukum). Setiap wakif mesti memenuhi persyaratannya sebagai berikut seperti: dewasa, berakal sehat, tidak terhalang melakukan perbuatan hukum, dan pemilik sah harta benda wakaf.

\section{Persepsi}

Faktor yang mempengaruhi persepsi ada faktor dari dalam dan dari luar atau objek dari persepsi itu sendiri. Setelah menerima informasi, rangsangan itu dipilih. Faktor dari dalam (internal) yang mempengaruhi pilihan persepsi seperti kebutuhan psikologis, latar belakang, pengalaman, kepribadian, keyakinan umum dan penerimaan diri. Faktor luar (eksternal) yang mempengaruhi adalah intensitas, ukuran, gerakan, ulangan, keakraban dan sesuatu yang baru (Efrizo, 2007)

Persepsi wakif pada wakaf tunai juga dipengaruhi oleh faktor-faktor yang terkait internal dan juga faktor eksternal. Seperti faktor pada wakif dalam memahami wakaf tunai adalah tingkat 
pendidikan, tingkat pendapatan dan mazhab yang diikuti wakif. Dan faktor eksternal yang mempengaruhi persepsi wakif tentang wakaf uang yaitu media informasi.

\section{METODE PENELITIAN}

Jenis penelitian yang peneliti lakukan ini adalah kualitatif deskriptif. Penelitian kualitatif yaitu merupakan penelitian deskriptif dan cenderung menggunakan analisis. Proses dan makna ditekankan dalam penelitian kualitatif. Landasan teori berfungsi sebagai alat bantu agar fokus penelitian sesuai dengan fakta di lapangan (Trianto, 2015). Berdasarkan penelitian di atas dapat diketahui penelitian ini bertujuan untuk menganalisis persepsi wakif terhadap wakaf tunai di BWI Sumatera Utara.

Lokasi penelitian di lakukan di BWI Sumatera Utara yang berlamat di Jalan A. H Nasution, Pangkalan Mansyur, Kompek Asrama Haji, Kecamata Medan Johor, Kota Medan.

Informan penelitian ini adalah orang yang hendak (akan) memberikan informasi terkait penelitian ini. Pada penelitian ini, informan penelitian terdiri dari 30 orang wakif dan 2 orang nazhir dari BWI Sumatera Utara, yakni Ketua BWI Sumatera Utara dan Anggota Divisi Pengelolaan dan Pemberdayaan Wakaf

Metode yang digunakan penulis dalam pengumpulan data penelitian yaitu wawancara serta dokumentasi. Penulis menggunakan analisis seperti reduksi data, penyajian data dan kesimpulan.

\section{HASIL DAN PEMBAHASAN}

\section{Deskripsi Penelitian}

Dalam penelitian ini penulis menyebarkan angket kepada para informan, yakni wakif yang mewakafkan uangnya kepada BWI Sumatera Utara. Adapun informan yang penulis ambil berjumlah 30 orang wakif di BWI Sumatera Utara.

\section{Demografi Penelitian}

Penelitian ini memberikan banyak gambaran proporsi informan jika dilihat dari jenis kelamin, usia, dan pendidikan dari pewakif yang berwakaf Tunai di BWI Sumatera Utara.

Tabel 1 Proporsi Responden Menurut Jenis Kelamin

\begin{tabular}{|c|l|c|c|}
\hline No & \multicolumn{1}{|c|}{ Gender } & Jumlah Responden & Proporsi \\
\hline 1 & Laki-Laki & 20 & $70 \%$ \\
\hline 2 & Perempuan & 10 & $30 \%$ \\
\hline & Jumlah & 30 & $100 \%$ \\
\hline
\end{tabular}

Sumber : Kuesioner, data diolah

Data informan berdasarkan hasil dari jenis kelamin (gender) berjenis kelamin laki-laki sebanyak 20 orang dan yang berjenis kelamin perempuan ada 10 orang, dan persentasenya laki-laki $70 \%$ dan persentase perempuan $30 \%$. 
Tabel 2 Proporsi Informan Berdasarkan Usia

\begin{tabular}{|c|c|c|c|}
\hline No & Umur & Total Informan & Proporsi \\
\hline 1 & $20-29$ & 4 & $13,3 \%$ \\
\hline 2 & $30-39$ & 15 & $50,0 \%$ \\
\hline 4 & $40-49$ & 9 & $30,0 \%$ \\
\hline 5 & $>49$ & 2 & $6,7 \%$ \\
\hline
\end{tabular}

Sumber : Kuesioner, data diolah

Berdasarkan hasil menurut usia responden yang berusia 20-29 tahun berjumlah 4 orang atau $13,3 \%$, yang berumur 30-39 tahun berbanyak 15 orang atau $50,0 \%$, dan yang berusia $40-49$ tahun ada 9 orang atau 30\% dan di atas 49 tahun berjumlah 2 orang atau 6,7\% orang Dari tabel di atas diketahui bahwa jumlah pewakif yang menjadi informan paling banyak adalah umur 3039 tahun.

Tabel 3 Proporsi Informan Berdasarkan Pendidikan

\begin{tabular}{|l|l|l|l|}
\hline No & Jenis Umur & Jumlah Respondennya & Proporsi \\
\hline 1 & SMP/MTS & 0 & $0,0 \%$ \\
\hline 2 & SMA/MA & 3 & $10,0 \%$ \\
\hline 3 & D1/D2/D3 & 9 & $30 \%$ \\
\hline 4 & S1/S2/S3 & 18 & $60 \%$ \\
\hline
\end{tabular}

Sumber : Kuesioner, data diolah

Dari hasil latar belakang pendidikan, pada jenjang pendidikan SMP/MTS ada 0 orang, jenjang pendidikan SMA/MA ada 3 orang atau $10 \%$, jenjang D1/D2/D3 ada 9 orang atau $30 \%$, dan jenjang S1/S2/S3 ada 18 orang atau $60 \%$.

Tabel 4 Proporsi Responden Menurut Pekerjaan

\begin{tabular}{|c|c|c|c|}
\hline No & Jenis Pekerjaan & Jumlah Responden & Proporsi \\
\hline 1 & Pegawai Swasta & 5 & $16,7 \%$ \\
\hline 2 & PNS & 7 & $23,3 \%$ \\
\hline 3 & Pegawai BUMN & 8 & $26,7 \%$ \\
\hline 4 & Wiraswasta & 10 & $33,3 \%$ \\
\hline
\end{tabular}

Sumber : Kuesioner, data diolah

\section{Persepsi Wakif Pada Wakaf Tunai}

Berdasarkan hasil angket dengan informan terkait persepsi wakif terhadap Wakaf Tunai di BWI Sumatera Utara, maka diperoleh hasil sebagai berikut : 
Tabel 5 Persepsi Wakif terhadap Wakaf Tunai di BWI Sumatera Utara

\begin{tabular}{|c|c|c|c|c|c|c|c|c|c|c|c|c|}
\hline \multirow{2}{*}{$\begin{array}{l}\text { Persepsi } \\
\text { wakif } \\
\text { Berdasarkan }\end{array}$} & \multicolumn{2}{|c|}{ STB } & \multicolumn{2}{|c|}{ TB } & \multicolumn{2}{|r|}{$\mathbf{N}$} & \multicolumn{2}{|r|}{ B } & \multicolumn{2}{|r|}{ SB } & \multicolumn{2}{|c|}{ Total } \\
\hline & $\mathbf{F}$ & $\%$ & $\mathbf{F}$ & $\%$ & $\mathbf{F}$ & $\%$ & $\mathbf{F}$ & $\%$ & $\mathbf{F}$ & $\%$ & $\mathbf{F}$ & $\%$ \\
\hline Pendapatan & 1 & $3.3 \%$ & 2 & $6.7 \%$ & 4 & $13.3 \%$ & 22 & $73.3 \%$ & 1 & $3.3 \%$ & 30 & $100 \%$ \\
\hline $\begin{array}{l}\text { Pemahaman } \\
\text { dan } \\
\text { Pengetahuan }\end{array}$ & 1 & $3.3 \%$ & 2 & $6.7 \%$ & 10 & $33.3 \%$ & 14 & $46.7 \%$ & 3 & $10.0 \%$ & 30 & $100 \%$ \\
\hline $\begin{array}{l}\text { Akses Media } \\
\text { Informasi }\end{array}$ & 1 & $3.3 \%$ & 1 & $3.3 \%$ & 13 & $43.3 \%$ & 10 & $33.3 \%$ & 5 & $16.7 \%$ & 30 & $100 \%$ \\
\hline Kemudahan & 2 & $6.7 \%$ & 2 & $6.7 \%$ & 8 & $26.7 \%$ & 14 & $46.7 \%$ & 4 & $13.3 \%$ & 30 & $100 \%$ \\
\hline Manfaat & 0 & $0.0 \%$ & 0 & $0.0 \%$ & 8 & $26.7 \%$ & 17 & $56.7 \%$ & 5 & $16.7 \%$ & 30 & $100 \%$ \\
\hline
\end{tabular}

Sumber : Kuesioner, data diolah

\section{Keterangan :}

$\begin{array}{ll}\text { STB } & \text { : Sangat Tidak Baik } \\ \text { TB } & \text { : Tidak Baik } \\ \text { N } & : \text { Netral } \\ \text { B } & \text { : Baik } \\ \text { SB } & \text { : Sangat Baik }\end{array}$

\section{Persepsi Wakif Terhadap Wakaf Tunai Dilihat Dari Indikator Pendapatan}

Dari jawaban responden yang disebar angket kepada 30 orang responden diperoleh hasil yaitu ada 1 responden menyatakan Sangat Tidak Baik dengan Wakaf Tunai dilihat dari indikator pendapatan persentasi 3,3\%. Ada 2 yang tidak baik dengan Wakaf Tunai dengan persentase $6,7 \%$. Ada 4 orang yang netral dengan Wakaf Tunai dengan persentase 13,4\%. Ada 22 orang yang menyatakan Baik dengan Wakaf Tunai dengan persentase $73,3 \%$, dan hanya satu yang menyatakan Sangat Baik dengan Wakaf Tunai yaitu 3,3\%.

Dilihat dari aspek pendapatan, disimpulkan 73,3\% informan menyatakan Baik. Yang artinya, wakif berpersepsi yang baik mengenai wakaf tunai, yakni dari indikator pendapatan maka wakaf tunai akan berkembang dan besar juga di dukung dari kesadaran masyarakat dalam mengembangkan ekonomi islam sehingga bahwa semakin sejahtera suatu negara (makro) maka pendapatan masyarakat juga semakin besar maka potensi wakaf tunai di BWI SU juga semakin besar.

Hasil penelitian ini relevan dengan penelitian terdahulu oleh Yuke Rahmawati (2010) yang berjudul Persepsi Wakif Dalam Berwakaf Tunai yang mengatakan bahwa indikator pendapatan dalam berwakaf tunai dimana wakaf tunai bervariasi jumlahnya sehingga masyarakat yang memiliki uang yang terbatas bisa mulai memberikan uangnya tanpa menunggu menjadi orang kaya atau mapan terlebih dahulu. Hasil ini sejalan dengan dengan Ahmad Nizar (2014) dan Cupian dan Nurun Najmi (2020). 


\section{Persepsi Wakif Terhadap Wakaf Tunai Dilihat Dari Indikator Pemahaman}

Dari Angket yang diedarkan terdapat satu pewakif yang menyatakan Sangat Tidak Baik dengan wakaf tunai dilihat dari indikator pemahaman dengan hasil persentasi sebesar 3,3\%. Dua responden menyatakan tidak Baik dengan persentase sebesar $6,7 \% .10$ orang menyatakan netral dengan persentase sebesar 33,3\%. 14 informan menyatakan Baik dengan persentase sebesar 46,7\% dengan Wakaf Tunai dari indikator pemahaman dan 3orang menyatakan Sangat Baik persentase sebesar 10\% terhadap Wakaf Tunai dari indikator pemahaman.

Jika persepsi dilihat dari indikator pemahaman tentang Wakaf Tunai, dapat disimpulkan bahwa 46,7\% informan menyatakan Baik tentang pemahaman mereka tekait pelaksanaan Wakaf Tunai. Artinya, wakif memiliki persepsi yang baik terhadap wakaf tunai sehingga muncul kesadaran dalam wakif untuk memajukan ekonomi islam melalui wakaf tunai.

Implikasi dari hasil penelitian ini terhadap penelitian sebelumnya dapat dilihat dari penelitian yang dilakukan oleh Budiman Wijaya (2021) yang mengatakan sebenarnya bahwa mahasiswa paham mengenai Wakaf Tunai tetapi belum memahami sepenuhnya, sehingga belum bisa berWakaf Tunai secara maksimal. Dari hasil penelitian ini dapat disimpulkan jika dilakukan penambahan literasi dan sosialisasi yang maksimal kepada para pewakif, sehingga wakif paham tentang Wakaf Tunai secara keseluruhan dan bisa membuat potensi Wakaf Tunai di Sumatera Utara dapat terealisasi secara maksimal.

\section{Persepsi Wakif Terhadap Wakaf Tunai Dilihat Dari Indikator Media Informasi}

Dari Angket yang diedarkan, satu orang menyatakan Sangat Tidak Baik dengan persentase 3,3\% dan Tidak Baik dengan hasil persentase yang sama terhadap Wakaf Tunai ditinjau dari akses media informasi, karena menurutnya akses media informasi diketahui daeri media massa/koran yang masih bersifat tradisional. 13 responden yang menyatakan pilihannya secara netral terhadap Wakaf Tunai ditinjau dari akses media informasi, yakni sebesar 43,4\%, menurut informan bahwa di era digital BWI SU lebih menggalakkan media informasi melalui media on line. 12 orang yang menyatakan Baik atau 40\% informasi didapatkan dari website resmi Badan Perwakafan dan lima orang yang menyatakan Sangat Baik sebesar 10\%. Dari informan mereka memperoleh informasi dan pemahaman yang cukup tentang Wakaf Tunai dari media informasi. Jika persepsi dilihat dari indikator akses media informasi.

Jadi disimpulkanlah bahwa 43,4\% responden (informan) menjawab netral. Artinya, BWI SU di era digitalisasi harus lebih menggalakkan media informasi melalui media on line. Hasil ini sejalan dengan dengan Ahamd Nizar (2014) dan Cupian dan Nurun Najmi (2020)

\section{Persepsi Wakif Terhadap Wakaf Tunai Dilihat Dari Indikator Kemudahan}

Dari Angket yang diedarkan dapat dilihat bahwa bahwa dua informan menyatakan Sangat Tidak Baik dengan Wakaf Tunai dilihat dari indikator kemudahan dengan persentase sebesar 6,7\%. Dua orang tidak Baik persentase sebesar 6,7\%. 8 orang netral persentase sebesar $26,6 \%$. 14 responden hasilnya menyatakan Baik dengan persentase sebesar 46,7\% dengan Wakaf Tunai dari indikator kemudahan dan empat orang menyatakan Sangat Baik dengan persentase sebesar 13,3\% terhadap Wakaf Tunai dari indikator kemudahan. 
Jika persepsi dilihat dari indikator kemudahan tentang Wakaf Tunai, dapat disimpulkan bahwa 46,7\% informan menyatakan Baik. Artinya, wakif memiliki persepsi yang baik tentang kemudahan yang diberikan dalam mengakses BWI SU untuk transaksi penghimpunan wakaf tunai bagi wakif.

Hal ini relevan dengan penelitian Harahap (2020). Hasil penelitian tersebut menyatakan produk wakaf pada Bank CIMB Niaga Syariah sudah cukup baik seperti sudah merespon kebutuhan para wakif, dengan merekomendasikan produk wakaf yang lebih jauh variatif, dan juga bekerja sama berbagai nazir dengan berbagai produk-produk wakaf, serta penerapan financial technologi. Semakin mudah seseorang berWakaf Tunai maka persepsi untuk berWakaf Tunai akan semakin baik.

\section{Persepsi Wakif Terhadap Wakaf Tunai Dilihat Dari Indikator Manfaat}

Dari Angket yang diedarkan dapat dilihat bahwa bahwa tidak ada informan menyatakan Sangat Tidak Baik dan tidak Baik. Delapan informan netral persentase sebesar 26,6\%. 17 orang menyatakan Baik dengan persentase sebesar 56,7\% dengan Wakaf Tunai dari indikator manfaat dan lima orang menyatakan Sangat Baik dengan persentase sebesar 16,7\% terhadap Wakaf Tunai dari indikator kemudahan.

Jika persepsi dilihat dari indikator manfaat tentang Wakaf Tunai, dapat disimpulkan bahwa $56,7 \%$ informan menyatakan Baik tentang manfaat yang diberikan tekait pelaksanaan Wakaf Tunai. Artinya, wakif memiliki persepsi yang baik tentang manfaat wakaf tunai dapat melatih jiwa sosial dan membantu umat yang kesulitan.

Implikasi Wakaf Tunai dari indikator manfaat juga telah dilakukan oleh Anisa Fitria Utami, Munawar Ismail (2014). Hasil penelitian Wakaf Tunai di Baitul Maal Hidayatullah dan Yayasan Dana Sosial Al-Falah belum cukup produktif. Dimana hasil Wakaf Tunai di ke-2 lembaga (badan hukum) dikelola dengan konsumtif, karena dana Wakaf Tunai langsung dijadikan menjadi seperti bangunan pondok pesantren dan mushaf Al-Qur'an. Persepsi wakif dari indikator manfaat sebenarnya baik, namun masih kurangnya literasi dan sosialisasi dalam pemanfaatan Wakaf Tunai dari indikator produktif sehingga potensi Wakaf Tunai dari indikator manfaat belum dapat terealisasi secara maksimal.

\section{KESIMPULAN}

Hasil penelitian menujukkan bahwa ada 5 indikator yang digunakan dalam mengukur persepsi wakif yaitu indikator internal yang terdiri dari pendapatan, pemahaman dan indikator ekternal yaitu media informasi, kemudahan dan manfaat wakaf tunai di BWI SU. Berdasarkan hasil penilaian angket data, bahwa 73,3\% wakif menyatakan baik dari indikator pendapatan. Artinya, wakif memiliki persepsi yang baik mengenai wakaf tunai bahwa semakin sejahtera masyarakat maka potensi wakaf tunai juga semakin besar. Dari indikator pemahaman menunjukkan 46,7\% wakif menyatakan baik dengan wakaf tunai. Artinya, wakif memiliki persepsi yang baik terhadap wakaf tunai dari sisi pemahaman sehingga muncul kesadaran dalam memajukan ekonomi islam melalui wakaf tunai. Dari indikator media informasi bahwa 43,3\% wakif menyatakan netral terhadap persepsi wakif dari sisi akses media informasi. Artinya, BWI SU 
agar lebih menggalakkan media informasi melalui media on line di era digital. Dari indikator kemudahan 46,7\% wakif menjawab baik. Artinya wakif memiliki persepsi yang baik tentang kemudahan yang diberikan dalam mengakses BWI SU untuk transaksi penghimpunan wakaf tunai bagi wakif. Dari indikator manfaat 56,7\% wakif menjawab baik. Artinya wakif memiliki persepsi yang baik tentang manfaat wakaf tunai dapat melatih jiwa sosial dan membantu umat yang kesulitan.

\section{DAFTAR PUSTAKA}

Cupian \& Najmi. (2020). Analisis Faktor-faktor yang Mempengaruhi Persepsi Masyarakat Terhadap Wakaf Uang di Kota Bandung. Jurnal Ilmiah Ekonomi Islam. ISSN: 2477-6157.

Djunaidi Achmad. (2004). Strategi Pengembangan Wakaf Tunai di Indonesia. Jakarta: Direktorat Pemberdayaan Zakat

Hadiduddin Didin. (2004). Hukum Wakaf. Jakarta: Al-Ilham Press

Harahap, M. I. (2019). Implementasi Produk Wakaf Uang Melalui Lembaga Keuangan Syariah (Studi Kasus Bank CIMB Niaga Syariah).

Harahap, M. I., \& Harahap, R. D. (2019). Analisis Faktor-Faktor Yang Memengaruhi Aset BPRS. Al-Tijaroh Jurnal Ilmu Manajemen Dan Bisnis Islam, 5(1), 67-82.

Harahap, R. D., Harahap, M. I., \& Syari, M. E. (2019). Pengarub Dau Dan Pad Terhadap Pertumbuban Ekonomi Dengan Belanja Daerah Sebagai. 5, 247-260.

Imsar. (2017). Ekonomi micro Islam. Medan: FEBI UINSU Press.

J Moleong Lexy. (2014). Metode Penelitian Kualitatif. Jakarta: Rosda Karya

Lis Sulistiani Siska. (2017). Pembaruan Hukum Wakaf di Indonesia. Bandung: Reflika Aditama

Nizar, A. (2014). Faktor-Faktor Yang Mempengaruhi Persepsi Wakif Tentang Wakaf Uang. Esensi: Jurnal Bisnis dan Manajemen, 4(1), 21-36.

Rahardjo. (2019). Oplimalisasi Wakaf Produktif Untuk Kesejabteraan Umat. Jakarta: Komite Nasional Keuangan Syaeiah

Rahmani, N. A. B. (2016). Metodologi Penelitian Ekonomi. Medan: FEBI UIN-SU Press.

Rasyid Sulaiman. (2001).Fiqh Islam. Bandung: Sinar Baru Algensindo

Robbins Stephen.(2007). Perilaku Organisasi Buku I. Jakarta: Salemba Empat

Sugiyono. (2018). Metode Penelitian Kuantitatif, Kualitatif, dan RひD. Alfabeta.

Trianto, B. (2015). Riset Modeling. Jakarta: Adh-Dhuha Institute. 